\title{
Particle topicalization and German clause structure
}

\author{
Andreas Trotzke ${ }^{1} \cdot$ Stefano Quaglia $^{2}$
}

\begin{abstract}
In this paper, we provide a comprehensive account of the phenomenon of topicalizing verb particles in German. Based on the data we discuss, we argue that only a version of the Split-CP hypothesis for the German clause can account for the observations. Section 1 critiques previous accounts of particle topicalization and discusses some properties of particles that are potentially relevant to topicalization. We conclude that a particle's ability to be topicalized depends more on its ability to be contrasted with other particles than on the semantic autonomy of the particle per se. Section 2 discusses unexpected cases of non-contrastable particles in the left periphery. In this context, we introduce a previously unnoticed phenomenon in which particle verbs denoting strongly emotionally evaluated situations allow their particles to be topicalized, even if the particle does not receive a contrastive interpretation. In Sect. 3, we show that an elaborated syntax of the German left periphery of the kind argued for in cartographic approaches is uniquely able to predict the distribution of topicalized particles.
\end{abstract}

Keywords Contrast · Emphasis - Expressive content · Left periphery · Particle verbs · Topicalization

Andreas Trotzke

trotzke@stanford.edu

Stefano Quaglia

stefano.quaglia@uni konstanz.de

1 Center for the Study of Language and Information, Stanford University, 210 Panama Street, Stanford, CA 94305, USA

2 Department of Linguistics University of Konstanz, Universitätsstraße 10, Constance 78464, Germany 


\section{Particle verbs: transparency and syntactic operations}

In the literature on particle verb constructions, it is generally claimed that at least two classes of particle verbs exist: transparent (i.e., compositional) and nontransparent (i.e., non-compositional, 'idiomatic') particle verbs (see McIntyre 2015 for a recent overview). It is not clear whether the class often referred to as 'aspectual particle verbs' can be subsumed under one of the two classes (cf. Jackendoff 2002 for treating aspectual cases as transparent; and Wurmbrand 2000 for a different proposal). In what follows, we approach the notion of semantic transparency from a syntactic perspective by focusing on syntactic phenomena that help to distinguish between transparent and non-transparent particle verbs. In the first section, we discuss accounts that refer to different syntactic behavior of particle verbs in the context of particle topicalization and predicative constructions (Sect. 1.1). In Sect. 1.2, we propose a new classification of particle verbs that provides a more fine-grained notion of semantic transparency. Crucially, we argue that the structural analyses given in Sect. 1.1 cannot account for the cases we will point out.

\subsection{A binary classification of particle verbs}

When looking at the transparency of particle verb constructions from a syntactic perspective, we observe that some rules of syntax are not sensitive to the divide between transparent and non-transparent particle verbs, e.g., particle shift in English:

(1) a. John kicks out the dog.

b. John kicks the dog out.

$(=$ transparent $)$

(2) a. John calls up his friend.

b. John calls his friend up.

(= non-transparent)

However, other processes are sensitive to the transparency distinction. Observe the following cases of particle fronting in English (cf. Jackendoff 2002: 75):

(3) a. Up marched the sergeant.

b. * Up blew the building.

In (3a), according to Jackendoff, the directional particle up is part of a nonidiomatic, transparent configuration and is thus licit in the locative inversion construction. In contrast, the idiomatic particle up in (3b) lacks the directional semantics and cannot be fronted.

As has been pointed out notably by both Wurmbrand (2000) and Zeller (2001), a similar situation obtains in German. In particular, while V2 is not sensitive to the transparency divide (4), topicalization of only the particle is. Compare the paradigms in (4) and (5) featuring the transparent aufmachen and the nontransparent aufhören (cf. Zeller 2001: 89 90). 
(4) a. (...) dass Hans die Tür aufmacht.

$(=$ transparent $)$

that Hans the door PART(open).makes

'... that Hans opens the door.'

b. Hans macht die Tür auf.

c. (...) dass Hans mit dem Trinken aufhört. (= non-transparent)

that Hans with the drinking PART(up).hears

'... that Hans stops drinking.'

d. Hans hört mit dem Trinken auf.

(5) a. Auf hat er die Tür gemacht (und nicht zu). (= transparent) PART(OPen) has he the door made and not PART(closed)

'He opened (not closed) the door.'

b. * Auf hat Peter mit dem Trinken gehört. (= non-transparent) PART(UP) has Peter with the drinking heard

'Peter stopped drinking.'

While in both aufmachen and aufhören the verb can move to $\mathrm{C}$ (stranding the particle and thus yielding a discontinuous structure, cf. $(4 b, d))$, topicalization may only target auf in aufmachen (5a) and not auf in aufhören (5b).

The phenomenon of particle topicalization has been extensively discussed in the literature on present-day Germanic, including English (cf. Dehé 2015 for an overview; and Müller 2002: 263 280, Zeller 2003 for relevant proposals). ${ }^{1}$ Recently, Trotzke et al. (2015) have provided empirical evidence from an acceptability study that fronting the particle of non-idiomatic particle verbs is a regular option in German syntax.

Crucially, topicalization patterns make clear that a distinction between transparent and non-transparent particle verbs has important reflexes in the grammar. The theories of particle verbs elaborated by Wurmbrand (2000) and Zeller (2001) place a premium on this observation. However, they differ in the way they represent the transparency spectrum in the grammar. On the one hand, Wurmbrand (2000) argues that the two classes are licensed in different structural configurations. On the other hand, Zeller (2001) postulates a uniform syntactic structure, relegating the transparency divide to constraints located at LF.

According to Zeller (2001: 127), particles are heads of non-functional phrasal complements. That is, the particle projects a phrase (and is hence in principle mobile), as can be seen in (6).

\footnotetext{
1 The (im)possibility of fronting the particle alone also plays a central role in the long standing debate on the component responsible for particle verb formation: are particle verbs built in the lexicon or in syntax? Under the assumption that sub constituents of syntactic atoms cannot be targeted by rules of syntax, topicalization is usually regarded as an argument in favor of the syntactic approach. Since, in this paper, we focus on the syntactic mobility of the particle, we adopt a syntactic approach.
} 
(6)<smiles>[Te]C1CC1</smiles>

Under this approach, both transparent and non-transparent particle verbs are represented in the same way.

Whereas Zeller accounts for the transparency divide by postulating a uniform phrasal representation in combination with an LF constraint, Wurmbrand (2000) proposes two different syntactic structures for transparent and non-transparent particle verbs. She argues that not all particle verbs instantiate the same structure: 'transparent' particle verbs are structurally different from '(semi)idiomatic' ones, according to her terminology. In particular, she proposes a structure such as (7a) for particle verbs like aufmachen and a configuration such as (7b) for cases like aufhören.

(7) a.<smiles>CCCCCC</smiles>

b.

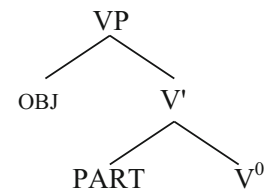

The tree for the compositional aufmachen (7a) features the verb machen taking a small clause (SC) containing a DP and a PartP, i.e., a phrase projected by the particle auf. The tree for the idiomatic aufhören (7b) is different: no SC is involved, and the particle auf is a direct complement of hören. Wurmbrand capitalizes on the observation that particles appearing in transparent particle verbs can serve as predicates in copular constructions (8a), while idiomatic particles cannot (8b).

(8) a. Die Tür ist auf.

the door is PART(open)

'The door is open.'

b. * Das Trinken ist auf. ${ }^{2}$

the drinking is PART(up)

In her approach, the two classes of particles thus differ in that transparent particles are licensed thematically (in a subject/predicate relation as represented by the SC structure), whereas non-transparent ones are licensed by a locality condition at LF, similar to what is proposed by Zeller (2001).

\footnotetext{
${ }^{2}$ Since Trinken was a prepositional object, this example from Zeller (2001) may raise additional issues (case, stative passive, etc.). An even clearer example in this context would be Das Turnier ist/wurde abgebrochen ('The tournament is/has been abandoned', lit. 'off broke'). Thanks to a reviewer for pointing this out.
} 
Let us now see what Wurmbrand's theory would predict with respect to particle topicalization. The relevant assumption (cf. Wurmbrand 2000: 16) is that topicalization is driven by a focus or topic feature (associated with a broad notion of contrast) on the topicalized item, to be checked in SpecCP. Since non-transparent particles cannot be construed contrastively (9b), they are not compatible with such a feature and are hence excluded from this syntactic operation in the first place. Particles in transparent configurations may be endowed with this feature because they can give rise to a contrast (9a).

(9) a. Er hat die Tür (auf-gemacht, zu-gemacht).

b. Er hat mit dem Trinken (auf-gehört, \#zu-gehört \#ab-gehört)

We will come back to this property in more detail below.

In this section, we saw that topicalization is a syntactic operation showing sensitivity to the semantic transparency of particle verbs. We sketched two accounts that assume that the differences between verb-particle classes must be represented in the grammar. Our discussion has indicated that both predicativity and contrastability are relevant for understanding the grammatical reflexes of transparency in the context of particle verbs. In what follows, we will show that we can gain an even finer-grained picture of the transparency spectrum of particle verbs by combining these two features.

\subsection{Detecting semantic transparency}

In what follows, we discuss the features employed by Trotzke et al. (2015) for operationalizing the notion of semantic transparency. The authors adopt two distinct binary features: [ \pm predicative] and [ \pm contrast]. The former is inspired by the 'particle entailment test' in (10), proposed by Lohse et al. (2004) for measuring the relation of dependency between the verb and the particle ( $i=$ independent; $\mathrm{d}=$ dependent $)^{3}$

(10) Particle entailment test

If [X V NP Pt] entails [NP PredV Pt], then assign $\mathrm{Pt}_{\mathrm{i}}$. If not, assign $\mathrm{Pt}_{\mathrm{d}}$.

PredV $=$ predication verb (BE, BECOME, COME, GO, STAY)

This test corresponds to Wurmbrand's (2000) proposal (see above) to refer to a particle verb as transparent if the particle can be a predicate in a copula construction. Of course, this is not the only way to test for relations of dependency between the verb and the particle. It has been demonstrated that the 'copula test' is too restrictive in the context of particle verbs. For instance, McIntyre (2002: 101) shows that motion verbs such as carry, rush, etc. combine compositionally with particles such as out or away, although many sentences with the respective particle verbs fail the copula test (cf. carry the ball away/out vs. *the ball is away/out).

\footnotetext{
${ }^{3}$ In what follows, we adopt the less technical notation by Lohse et al. The test in (10) must be understood as involving a material implication between the denotations of sentences (which in Lohse et al.'s notation are signaled by square brackets and here correspond to truth values).
} 
Crucially, in these cases only more idiomatic usages of particles such as out pass the copula test (cf. she is out in the sense of 'not at home'), see also Cappelle (2008: 137 139) on the insufficiency of the copula test. Similar cases in German show that the copula test is not fully sufficient for determining the semantic autonomy of a particle.

However, in what follows we merely want to demonstrate that criteria of semantic autonomy as such do not suffice to cover the aspects of particle semantics that seem to be relevant for topicalization patterns. To make a strong case for this argument, it is heuristically useful to force a binary coding in the form of entailment tests such as (10), although we are aware of the fact that semantic autonomy is a graded concept. Accordingly, we employ the broad version of the copula test by Lohse et al. (2004), using several kinds of predication verbs. Given these diagnostics, we can distinguish [+autonomous] cases ('independent', in Lohse et al.'s terminology) such as (11) from [-autonomous] cases ('dependent') like (12).

(11) a. die Tür auf-machen

b. Die Tür ist auf.

(12) a. mit etwas auf-hören ('to stop something', lit. 'to up-hear')

b. * Etwas ist auf.

Although there is a long tradition claiming that only particles that correspond to copula particles can be topicalized (cf., e.g., Engel 1977: 213), we already saw in Sect. 1.1 that the notion of contrast is of crucial relevance for understanding topicalization patterns of particle verbs. This is a quite robust generalization arrived at in the literature devoted to the topic (cf. Müller 2002: 276 277; Zeller 2001: 93 99, 2003 among others). To operationalize the notion of contrast in this context, Trotzke et al. (2015) propose the test in (13), which we present here in more detail in (14):

(13) Particle contrastability test

Assign a particle Prt (in a particle verb [Prt V]) the feature [+contrast] iff Prt triggers a set of alternatives different from the empty set.

(14) Particle contrastability test

In a particle verb $\left[\operatorname{Prt}_{i} \mathrm{~V}_{j}\right]$, assign a particle $\operatorname{Prt}_{i}$ the feature $[+$ contrast $]$ iff:

a) the ordered pair $\left.<\operatorname{Prt}_{i}, V_{j}\right\rangle$ is a member of a set of alternatives, defined as the set $\mathrm{M}$, containing all ordered pairs $\left.<\operatorname{Prt}_{\mathrm{x}}, \mathrm{V}_{\mathrm{y}}\right\rangle$ such that:

(i) any two instantiations of $\operatorname{Prt}_{\mathrm{x}}$ have a different denotation, and any two instantiations of $\mathrm{V}_{\mathrm{y}}$ have the same denotation, and

(ii) any two pairs instantiating $<\operatorname{Prt}_{\mathrm{x}}, \mathrm{V}_{\mathrm{y}}>$ have a different overall denotation, and

b) the cardinality of $M$ is $\geq 2$. 
The test given in (14) accounts for the data we already discussed in (9) above, repeated here for convenience. In particular, in (15a) the particle auf is a member of a set of alternatives where the meaning of $\mathrm{V}$ (machen) is constant. Accordingly, auf bears the feature [+contrast]. In (15b), however, the particle auf is not a member of a set of alternatives where the meaning of V (hören) is constant. It is thus marked as [-contrast]. Note that hören in aufhören does not have the meaning 'to hear'. If it does, however, the particle $z u$ can form a set of alternatives $(15 \mathrm{c})$ and thus bears the feature $[+$ contrast $]$.

(15) a. (auf, zu)-machen

'to open/to shut'

b. (auf, \#zu)-hören

'to stop/to listen'

c. (zu, weg)-hören

'to listen/to not listen'

In sum, since the notion of transparency is thus decomposed into two separate features, it is possible to test for the existence of all four logical combinations.

Crucially, the values for semantic autonomy with predication verbs and for the property of contrastability do not always correlate. That is, the class of [+autonomous] particle verbs is not coextensive with the class of [+contrast] particle verbs. On the other hand, the feature [-autonomous] does not correspond to the feature [-contrast]. First, consider (16), where the particle has no autonomous denotation, but a contrast is nevertheless possible (cf. ab-nehmen vs. zu-nehmen).

(16) Nein, nicht ab muss er nehmen, sondern zu. (Müller 2002: 265) no not PART(off) must he take but PART(on)

'He must gain weight, not lose weight.'

The literature mentions several other cases of topicalizing the particle where the fronting of semantically non-autonomous particles (according to the copula test) is possible as long as a contrast is established between two particles functioning with the same verb, cf. (17) from Lüdeling (2001: 53) and (18) from Müller (2002: 276):

(17) Auf geht die Sonne im Osten, aber unter geht sie PART(Up) goes the sun in.the east but PART(down) goes she im Westen

in.the west

'The sun rises in the east, but sets in the west.'

(18) Nicht um färbt Karl den Stoff, sondern ein. not PART(around) dyes Karl the cloth but PART(in)

'Karl is not dyeing the cloth a different color. He is dyeing it for the first time.'

Second, we find cases where the particle has an autonomous denotation, but the particle cannot be a member of an alternative set. 
(19) Er hat das Schloss aufgebrochen. (Stiebels 1996: 160 161) he has the lock PART(open).break

'He broke open the lock.'

We thus conclude that both contrastability and semantic autonomy are relevant in measuring the semantic transparency of particle verbs.

In sum, it seems that an approach is needed which not only distinguishes between fully transparent (11) and fully non-transparent (12) particle verbs, but also identifies intermediate classes, which capture different degrees of dependency between the verb and the particle. It is not clear how the proposals we sketched in Sect. 1.1 can capture the transparency spectrum we thus identified. In particular, theories suggesting a binary distinction do not address the diverse classes of particle verbs we indicated in this section. As we will show in what follows, the picture is even more complicated by an additional class of particle verbs that cannot be identified by reference to the transparency diagnostics pointed out in the literature.

\section{Beyond semantic transparency: expressive patterns of particle topicalization}

In this section, we discuss rather unexpected cases of non-contrastable particles in the left periphery. We then establish a novel grammatical distinction between expressive and non-expressive particle verbs. Our claim is substantiated by a set of dedicated grammatical phenomena that justify this distinction.

In Sect. 1.1, we mentioned that syntactic approaches acknowledge that an important grammatical reflex of the distinction between (fully) transparent (in our system: [+contrast, +autonomous]) and (fully) non-transparent ([-contrast, -autonomous]) particle verbs is the option of topicalizing the particle (cf. (5) above). However, several examples discussed in the literature and certain cases reported in the empirical study by Trotzke et al. (2015) show that there is an indication that not all [-contrast, -autonomous] particle verbs behave equally with respect to topicalization.

Let us first turn to examples from the literature. The following cases are instances reported in the corpus studies by Müller (2002) and Heine et al. (2010) ${ }^{4}$ :

(20) a. Auftritt im blauen Anzug der König. (Müller 2002: 273) PART(up).steps in.the blue suit the king

'The king appears in a blue suit.'

b. Richtig auf regt mich im Moment, wie der arme Gomez very PART(Up) move me in.the moment how the poor Gomez. von den Medien fertig gemacht wird. from the media ready made becomes (Heine et al. 2010: 41) 'It really upsets me how Gomez is clobbered by the media.'

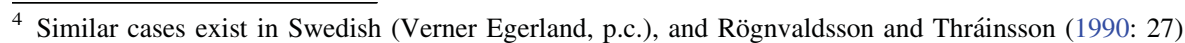
report that such patterns are very common in Icelandic.
} 
c. An haben wir damit gefangen, daß... (Müller 2002: 277) PART(up) have we therewith caught that

'We got started on this by talking about...'

In all three cases, the topicalized particle can be classified as [-autonomous] and cannot establish a contrastive reading. However, we observe that fronting the particle has other effects for structuring the information conveyed by the sentences. In particular, (20a), actually a stylistic archaism, is a case of 'presentative focus' where an entity following the particle verb is introduced in the discourse. In other words, due to topicalizing the particle, the focus of the sentence is shifted onto the subject der König, which can now occupy the rightmost position in the clause. In the literature, it has been claimed that such presentative foci are often used in utterances in which a sentence contains new information as a whole. According to Hetzron (1975), such sentences can be said to contain only a rheme, or, in other words, these utterances are thetic judgments without a clear partitioning between new and given information. This is best exemplified by (20b), which is, according to Heine et al. (2010: 48), a clear case of an all-sentence focus. (20c) shows that this interpretive option is also available when the particle and the verb occur non-adjacently, as in our examples in the preceding sections.

These observations can be related to Erteschik-Shir's (2007) notion of 'altruistic fronting'. She argues that sometimes elements that neither function as a topic nor as a narrow (e.g., contrastive) focus (i.e., elements like our non-contrastable verb particles) can be fronted to impose a thetic or 'all-focus' interpretation. This phenomenon can also be found in German examples like (21), in which speakeroriented adverbs are fronted, cf. Erteschik-Shir (2007: 114):

(21) Leider hat keiner dem alten Mann geholfen. unfortunately has nobody the.DAT old man helped 'Unfortunately, nobody has helped the old man.'

In this case, as Erteschik-Shir points out, the movement is 'altruistic', insofar as the fronting of the adverb is not triggered to satisfy a particular semantic or pragmatic requirement of the moved element itself (cf. also Sect. 3.2 below), but to induce a particular interpretation of the whole construction by forcing a thetic focus structure with a stage topic, see also Lambrecht (2000) in this regard. In sum, in these cases of fronting information-structurally inert elements, the structure can differ in information structure from a structure in which these elements remain in situ in that the sentence is marked as being all focus and having a stage topic.

Crucially, Leonetti and Escandell-Vidal (2009) have observed that fronting yielding structures containing no informational partition can also be a means of expressing an emphatic/exclamative value. That is, some structures displaying allsentence emphasis come close to sentence exclamations showing the same lack of informational partitioning. In what follows, we will illustrate that fronting of noncontrastable verb particles in German can also yield such emphatic interpretations. In particular, we will discuss a new observation that lends support to the idea that 
fronting of some non-contrastable particles is particularly suitable for adding a thetic and exclamatory character to the utterance.

In addition to the cases mentioned above, Trotzke et al. (2015) showed that topicalization in cases such as runter-machen ("to put sb. down, to heavily criticize sb.') are more acceptable than cases such as aufhören (cf. (5b) above). That is, in cases of non-transparent particle verbs occurring non-adjacently, acceptability judgments vary considerably. Looking at the mean judgments of the individual nontransparent particle verbs in non-adjacent position, Trotzke et al. found that the three verbs nach-geben 'to give way under pressure', auf-machen 'to head off', and auf-fliegen 'to be revealed, to become public' were all judged at or below $20 \%$ on a scale of acceptability ranging from $0 \%$ (= very bad) to $100 \%$ (= very good). In contrast, the verb runter-machen received a rating of above $40 \%$. That is, in the context of Trotzke et al.'s study, fronting the particle of the non-transparent particle verb runtermachen received the same rating as the fronting of particles of transparent particle verbs (such as zu-machen 'to close').

$$
\begin{array}{lllll}
\text { RUNTER hat sein Chef ihn vor allen Kollegen gemacht! } \\
\text { PART(down) has his boss him in.front.of all colleagues made }
\end{array}
$$
'His boss put him down/heavily criticized him in front of all his colleagues.'

(23) ? NACH hat der Hans dann endlich gegeben! PART(to) has the Hans then finally given

'Hans finally conceded.'

The effect we see in (22) is not predicted by the information structural constraints mentioned in Sect. 1, according to which all fully non-transparent particle verbs should behave alike. An obvious account in the case of runter-machen would be to follow Stiebels and Wunderlich (1994), who argue that topicalization of resultative or directional particles (like runter) improves the acceptability of such constructions. They substantiate their claim by giving examples such as (24), showing that fronting is only possible if the particle licenses a resultative or directional interpretation:

(24) (Weit) hinaus ist der Ball geworfen worden. far PART(out) is the ball thrown got 'The ball was thrown far out.'

We hypothesize, however, that this is not the whole story. Observe the following authentic examples, which, as we want to claim, pattern with the case given in (22): 
(25) a. Aber ich kann mich nicht hier über ihn so sehr beschweren but I can myself not here about him so much complain und ihn gleichzeitig in meiner Kontaktliste behalten. and him at.the.same.time in my address.list keep Raus ist er geflogen! PART(out) is he flown

'However, I cannot complain about him so much and at the same time keep him in my contacts. He got kicked out!'

$<$ https://shaarazad.wordpress.com/tag/bewerbung $>$

b. Aber zur Tür raus ist er geflogen. Und zwar mit but to.the door PART(out) is he flown and namely with einem Startschub von meinem Fuss in seinen Hintern! a starting.push of my foot in his bottom

'However, he got kicked out of the door namely by a kick in his pants!' $<$ http://rowicus.ch/Wir/BilderWerke/Gagarosto.pdf >

(26) Jetzt wird die auch noch belohnt. Wofür. Raus sollte man now gets she even also rewarded what.for PART(out) should one sie schmeißen. Wenn ich im Haus wäre(,) ich wär schon her throw if I in.the house were I were already lange geplatzt.

long burst

'Now she is even rewarded. But what for? One should kick her out! If I were in this house, I would have burst with anger already well before.' $<$ http://www.bigbrother-aktuell.info/board161-big-brother-was-fr-hereinmal-war/board135-big-brother-8/board141-big-brother-8-die-exbewohner/5779-bianca/index7.html >

Neither rausfliegen nor rausschmeißen can be contrasted in their idiomatic readings in (25) and (26) (cf. \#reinfliegen and \#reinschmeißen). What both verbs have in common with the example featuring runtermachen is that these particle verbs all name strongly emotionally evaluated situations ('to criticize someone heavily', 'to get rid of someone in a harsh way', etc.). Crucially, if we contrast one of these verbs with a 'less expressive' particle verb containing the same particle, we observe a clear decrease in acceptability in the non-expressive cases (see Trotzke and Wittenberg 2016 for experimental evidence). Observe the following contrast:

(27) Stell Dir vor! ('Guess what!'):

a. RAUS hat Costa Rica die Engländer geschmissen! PART(out) has $C . \quad R$. the English.PL thrown

'The team of Costa Rica kicked out the English team.'

b. ? RAUS hat die Band ihr neues Album gebracht! PART(out) has the band their new album brought 'The band published their new album.' 
The particle raus can be topicalized in (27a) and not in (27b), although both rausschmeißen (27a) and rausbringen (27b) feature particles with a clear directional semantics. Accordingly then, the difference must be due to another factor. We can make sure that the difference is not due to compositionality issues in terms of semantic transparency, given our classification in Sect. 1.2. In particular, the particle in both rausschmeißen and rausbringen bears the same feature specification, i.e., [-contrast, +autonomous]:

(28) $[$ - contrast $]$

a. (raus, \#rein)-schmeißen

b. (raus, \#rein)-bringen

(29) [+autonomous]

a. Die Engländer sind raus.

'The English team is out.'

b. Das neue Album ist raus.

'The new album is out.'

Given that we can thus exclude reasons of semantic transparency, the question arises what kind of additional factors license particle topicalization in cases such as (27a).

Let us turn to the cases given in (27) in more detail. While rausschmeißen entails that a team has eliminated a competitor in a stunning way, rausbringen does not refer to any such remarkability scale that could serve as the basis for expressing evaluation by the speaker: either the band published or did not publish their album. This parallels observations by Rett (2015: 147 172), who shows that evaluative implicatures of several marked constructions, such as the topicalization patterns in (27), are connected to the property that the at-issue content of the utterance is somehow remarkable.

Crucially, one could imagine a context where (27b) is not that bad. For example, in a case where a band is known to spend many years in the studio before releasing a new album, the speaker might express his surprise about the fact that, this time, the publishing process has been completed very fast. However, in this case, as the scenario makes very clear, the violation of the speaker's expectation is based on a likelihood ranking with regard to the speed of publishing of that particular band. In other words, the otherwise 'binary' option of publication (to either publish or not publish) is enriched by a degree dimension connected to the factor 'speed'. In what follows, let us turn to this degree component in more detail.

In the preceding discussion, we showed that particles of fully transparent particle verbs are not the only particles that can be fronted. Rather, we showed that fronting non-contrastable particles results in a thetic statement that can have the flavor of a sentence exclamation. This interpretation is particularly present in cases such as runtermachen (22) or rausschmeißen (26, 27a). These particle verbs entail a remarkability component which makes them felicitous in a construction that is associated with the interpretation of unexpectedness on the part of the speaker. 
Verbs like rausbringen, on the other hand, need a special context to be licensed in such an exclamatory fronting construction.

To show that we are dealing with a distinct class of particle verbs in the cases of rausschmeißen, runtermachen, etc., we turn to diagnostics from adjectival semantics. Note that certain 'extreme' degree modifiers only occur with adjectives that can be analyzed as conveying expressive or extreme content. This is shown by the contrast given in (30), cf. Morzycki (2012: 568):

(30) a. Your shoes are (downright, positively) (gigantic, gorgeous).

b. ?? Your shoes are (downright, positively) (big, pretty).

An adjective like gorgeous is lexically expressive and thus can combine with, e.g., downright very naturally. This type of extreme degree modification also contributes to the expressive (and thus, according to Potts 2007, to the non-at-issue) meaning dimension. For instance, Morzycki (2012: 596 597) argues that expressives (31) and extreme degree modifiers (32) behave in parallel concerning their embeddability:

(31) a. ?? He isn't fucking calm.

b. ?? If he's fucking calm, you could try poking him with this stick.

(32) a. ?? Murderers aren't downright dangerous.

b. ? Are murderers downright dangerous?

c. ? If murderers are downright dangerous, you might want to avoid Harold.

Turning to the particle verb constructions again, we can apply these diagnostics to the non-transparent particle verbs discussed above. As can be seen in (33), both rausschmeißen (33a) and runtermachen (33b) accept extreme degree modifiers such as regelrecht ('downright'), whereas particle verbs like rausbringen are not compatible with such modifications (33c).

(33) a. Costa Rica hat die Engländer regelrecht rausgeschmissen.

C. $R$. has the English.PL downright PART(out).thrown

'The team of Costa Rica downright kicked out the English team in the world championship.'

b. Sein Chef hat ihn regelrecht runtergemacht. his boss has him downright PART(down).made

'His boss downright put him down/heavily criticized him.'

c. ?? Die Band hat ihr neues Album regelrecht rausgebracht. the band has their new album downright PART(out).brought 'The band downright published their new album.'

Given what we said concerning the expressive contribution of these modifiers, we thus see that certain particle verbs are expressive, while others are not. 
An additional piece of evidence that suggests that our distinction is on the right track comes from the compatibility with $w h$-exclamatives featuring non-argumental wh-elements like was ('what') in (34).

(34) Was sind die Fußballer verrückt!

what are the soccer.players crazy

'How crazy the soccer players are!'

The pattern we observe here parallels the one we observed in the context of degree modification:

(35) a. Was hat Costa Rica die Engländer rausgeschmissen!

what has C. $R$. the English.PL PART(out).thrown

'How Costa Rica kicked out the English team!'

b. Was hat sein Chef ihn runtergemacht!

what has his boss him PART(down).made

'How his boss put him down/criticized him!'

c. ?? Was hat die Band ihr neues Album rausgebracht!

what has the band their new album PART(out).brought

'How the band published their new album!'

To sum up, we showed that fronting of non-contrastable particles can change the information structure of a sentence by avoiding a narrow split between topic and comment or focus and background, respectively. We then demonstrated that this elimination of a narrow informational partitioning can result in exclamatory statements, especially in the context of expressive particle verbs. This class of particle verbs denotes strongly emotionally evaluated events and is thus particularly suitable for forming a fronting construction that conveys an all-sentence focus with an exclamatory flavor. In other words, the unexpectedness component expressed by these constructions needs less extra context with verbs that lexically entail an event that is remarkable as such. We established the new class of expressive particle verbs by means of three types of grammatical phenomena. First, we demonstrated that expressive particle verbs more easily allow topicalization of non-contrastable particles. Second, we showed that only expressive particle verbs are compatible with extreme degree modification. Third, and related to the latter property, we pointed out that only this distinct class is felicitous in $w h$-exclamatives with was.

In what follows, we explore to what extent all the distinctions between verbparticle classes discussed in the previous sections must be represented in the grammar, since it is not clear how current structural approaches (cf. Sect. 1.1) can account for the diversity we illustrated concerning the grammatical behavior of different particle verb classes. We turn especially to the syntax of the left periphery and show how the fronting of non-contrastable particles can be implemented in German clause structure. 


\section{Particle topicalization and German clause structure}

In this section, we first address the general issue concerning the syntactic representation of verb particles. We turn to each of the distinctive features of the different particle verb classes we pointed out above. Specifically, we address the features of autonomy, contrastability, and expressivity (Sect. 3.1). Finally, we come back to the puzzling topicalization patterns in the context of non-contrastable particles and propose a unified account for the topicalization of particles to the left periphery (Sect. 3.2).

\subsection{Idiomaticity and the derivation of the clause}

Let us first consider how the different interpretive properties of particle verbs we have pointed out so far can be accounted for in the derivation of the clause. In the preceding sections, we observed that mobility of the particle is attested in every transparency class.

(36) a. AUF hat er die Tür gemacht!

$(=5 \mathrm{a})$ [+contrast, +autonomous]

b. Nein, nicht $\mathrm{AB}$ muss er nehmen, sondern ZU! (=16) [+contrast, -autonomous]

c. RUNTER hat sein Chef ihn vor allen Kollegen gemacht! (=22) [-contrast, - autonomous]

d. RAUS hat Costa Rica die Engländer geschmissen! (=27a) [-contrast, +autonomous]

We therefore adopt the representation given in (37) as a null hypothesis:

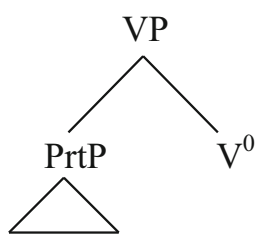

Starting from this structural claim, we will now turn to each of the relevant features of our different particle verb classes. We first turn to the feature [ \pm autonomous].

As pointed out in Sect. 1.1, Wurmbrand (2000) associates a small-clause structure to her class of transparent particle verbs. She thus capitalizes on the predicate/argument relation between particle and THEME when accounting for semantic transparency. This holds for cases such as aufmachen vs. aufhören, as already shown in (7) and (8), repeated here for convenience: 
(38) a

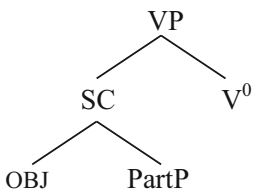

b.

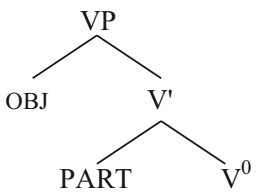

(39) a. Die Tür ist auf.

b. * Das Trinken ist auf.

In our transparency classification, however, the presence or absence of a smallclause representation is only justified as a correlate of the feature [ \pm autonomous]. In other words, we argue that a bijective correlation between transparency and a small-clause representation, as suggested by Wurmbrand (2000), does not hold. That is, a small-clause structure like (38a) not only obtains for fully transparent particle verbs like aufmachen ([+contrast, +autonomous]), but also for the intermediate class exemplified by aufbrechen ([-contrast, +autonomous], cf. (19) above).

Let us now address the feature [ \pm contrast]. Based on her binary distinction between transparent and non-transparent ('(semi)-idiomatic') particle verbs, Wurmbrand (2000) suggests that all semi-idiomatic particles lack features such as focus or topic, realizing the information structural notion of contrast. However, as we already showed in Sect. 1.2, partially idiomatic particles can also be construed contrastively, as shown in (40). $\begin{array}{llllll}\text { (40) Nein, nicht ab } & \text { muss er nehmen, sondern } & \text { zu. } \\ \text { no not PART(off) } & \text { must he take } & \text { but } & \text { PART(on) }\end{array}$ 'He must gain weight, not lose weight.'

In our approach, the existence of such a class ([+ contrast, -autonomous] $)$ is not ruled out, since contrastability is only one component of transparency. Accordingly, the particle should be analyzed according to our uniform representation in (37). ${ }^{5}$

We thus see that the representation of semantic aspects like argument structure (as in (38)) cannot be correlated with patterns we see in the context of the contrastability of a particle. In other words, at the level of VP, it is reasonable to assume that predicate-argument relations of particle verbs are structurally represented, but it is conceptually unattractive to postulate the existence of a designated projection for the encoding of the lexical component of the contrastability of the respective particle. Accordingly, we claim that not all features defining the transparency spectrum of particle verbs can be represented in the syntactic structure. We thus argue that interpretive features like contrastability are checked at a later

\footnotetext{
5 Note that nothing in our analysis hinges on the discussion of the phrasal status of particles. In this section, we merely want to point out that the features of idiomaticity we discussed in this paper are distributed over the derivation of the clause. Discussing the phrasality of particles has become less important, given current relational approaches to phrase structure and the underlying "minimalist assumption that phrase structure representation is 'bare', excluding anything beyond lexical features and objects constructed from them" (Chomsky 1995: 245).
} 
stage of the derivation. This is in accordance with Zeller (2001, 2003), who argues that 'special' verb meanings that are only activated in the context of particle verb combinations are not licensed before the structure is spelled out at LF. Consider examples like the following, cf. Zeller (2001: 204):

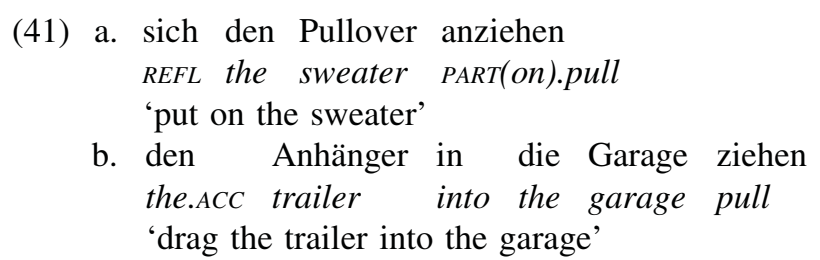

In (41a), the verb ziehen 'to pull, to drag' adopts a special meaning that is conceptually compatible only with a subset of the possible internal arguments licensed by the literal interpretation we see in (41b).

If this approach is on the right track, the interpretive effects concerning expressivity of particle verbs (Sect. 2) can be explained along these lines, too. Observe first the following pair, where the particle verb reinziehen is interpreted either idiomatically or fully compositionally:
a. sich eine Flasche Bier reinziehen REFL one bottle beer PART(in).pull 'to drink one bottle of beer in one go/to guzzle a beer'
b. den Anhänger reinziehen (in die Garage) the.ACC trailer PART(in).pull into the garage 'to drag in the trailer'

Note that (42a) is expressive in the sense discussed in Sect. 2, while (42b) is not, as evidenced by the compatibility with modifiers such as regelrecht 'downright' or total 'full-on':

(43) a. sich eine Flasche Bier regelrecht/total reinziehen

b. ?? den Anhänger regelrecht/total reinziehen

This suggests that not only features like contrast, deciding between literal or special readings, should be formulated as LF constraints, but also expressive readings. The overall picture suggests that idiomaticity can be decomposed into many facets which can be distributed over the syntactic derivation. That is, some features (like autonomy as evidenced by predicativity) are encoded directly in the syntactic representations, while others (like both contrast and expressivity) are checked at the later stage of Spell-Out at LF. In terms of grammatical architecture, our proposal shares basic assumptions with current models allowing multiple access to the lexical component (e.g., Gallego 2010; Trotzke 2015). The different patterns we observe in the context of particle verbs can be implemented as conditions on wellformedness/coherence to be checked against the relevant sub-component of the lexicon. Arguably, lexico-semantic paradigms are relevant for contrast, whereas the 
encyclopedia may be relevant for expressiveness. With this aspect of particle verb interpretation in mind, let us now turn to particle topicalization and the syntax of the left periphery.

\subsection{Particle topicalization and emphatic fronting}

\subsubsection{Emphatic frontings are not exclamatives}

As we pointed out in Sect. 1.1, topicalization patterns make clear that the distinction between transparent and non-transparent particle verbs has important reflexes in the grammar. However, our data in the previous sections suggest that there is more to topicalization than semantic transparency as defined in the literature. In what follows, before we turn to the exact implementation in the left periphery, we discuss a possible hypothesis concerning the clausal type of the utterances involving nontransparent particle verbs discussed in Sect. 2. Aiming at a deeper theory of emphatic fronting, one has to take seriously the exclamative-like interpretational properties, especially of the cases involving expressive particle verbs.

As is well known, exclamatives can trigger T-to-C movement (Does that hurt!) and we also find 'exclamative particles' before the finite verb (Boy, does that hurt!). It is thus tempting to assume that the fronting constructions exemplified in Sect. 2 are a kind of exclamative where the position before the finite verb is not filled by an exclamative particle, but rather by a non-contrastable particle. In what follows, however, we argue that our cases of emphatic fronting are not exclamatives in this sense, but rather sentence exclamations. Consider the following difference between sentence exclamations (44) and exclamatives (45 47) pointed out by Rett (2011: 414):

(44) A: (Wow,) John bakes delicious desserts!

B: No (he doesn't), these are store-bought. John's actually a terrible cook.

(45) A: (My,) What delicious desserts John bakes!

B: ? No (he doesn't), these are store-bought. John's actually a terrible cook.

(46) A: (Boy,) Does John bake delicious desserts!

B: ? No (he doesn't), these are store-bought. John's actually a terrible cook.

(47) A: (My,) The delicious desserts John bakes!

B: ? No (he doesn't), these are store-bought. John's actually a terrible cook.

According to Rett (2011) and many others, while a sentence exclamation like (44) additionally counts as an assertion, this does not hold for the exclamative cases in (45 47). Note now how our cases of particle topicalization pattern with regard to this central diagnostics: 
(48) A: Stell Dir vor! ('Guess what!'):

RAUS hat Costa Rica die Engländer geschmissen!

PART(out) has C. $R$. the English.PL thrown

'The team of Costa Rica kicked out the English team.'

B: No (they didn't). England actually won the match.

(49) A: Was hat Costa Rica die Engländer rausgeschmissen!

what has $C . \quad R$. the English.PL PART(out).thrown

'How Costa Rica kicked out the English team!'

B: ? No (they didn't). England actually won the match.

In accordance with Rett (2011), we see that (48), as a sentence exclamation, additionally asserts a proposition $\mathrm{p}$, while (49), as an exclamative, does not make a contribution to the discourse that could be denied or affirmed directly. In sum, we conclude that our cases of emphatic fronting involving non-contrastable particles should not be analyzed along the lines of exclamatives such as Boy, does that hurt!

In addition to the argument concerning the assertive force of sentence exclamations compared to exclamatives, we see that exclamative particles such as boy are totally optional, see Elliott (1974: 243) and subsequent work. Also, they are prosodically disintegrated (Corver 2015), unlike our cases of particle fronting. And lastly, productive modification of boy along the lines of particle modification with, e.g., regelrecht is not possible in the interplay between interjections and exclamatives (see the empirical survey by Norrick 2009: 879 880).

However, what exclamatives and sentence exclamations such as our emphatic fronting constructions have in common is that they convey the expression that a proposition $\mathrm{p}$ has violated the speaker's expectation. In the next section, we will explore to what extent this notion of 'unexpectedness' should be represented in the left periphery of the German clause.

\subsubsection{The derivation of emphatic fronting in German}

Turning to the derivation of emphatic fronting that involves particle topicalization in German, we first have to distinguish between pragmatically relevant and nonrelevant cases of preposing a constituent to the prefield. In German, constituents like subjects or frame adverbials can show up in the left periphery of the clause without receiving any special pragmatic interpretation. However, as Frey (2004a: 12 15) points out, the left periphery of course can also host topical material, as shown in (50):

(50) I will tell you something about Max.

Den Max sollte unsere Gruppe unterstützen.

the.ACC Max should our group support

'As for Max, our group should support him.' 
Crucially, as Frey argues, topical material, before being moved to the left periphery, has already undergone a movement operation. Specifically, den Max receives a topical interpretation already in the middle field of the German clause (for an elaboration on this topic position, see Frey 2004b):

(51) a. ... dass ('that') den Max unsere Gruppe unterstützen sollte.

b.

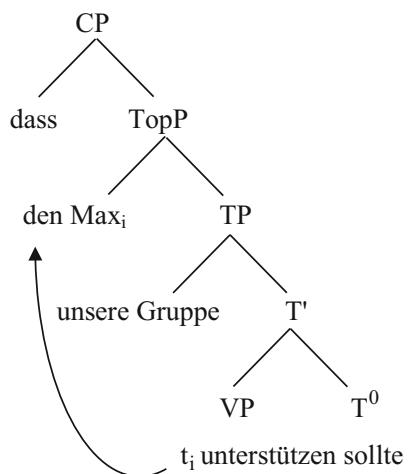

According to Frey, the constituent den Max is the closest one to the specifier of CP, and, under this hypothesis, is the first (and hence the only possible) target for Formal Movement (for this notion, see Fanselow 2003), as represented in (52):

$(52)$

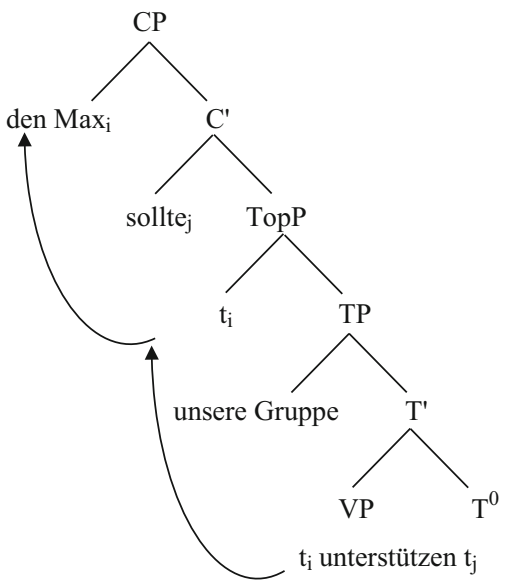

Accordingly, movement to the left periphery in this case "does not seem to be related to any semantic or pragmatic property but seems to be a purely formal one" (Frey 2004a: 8). Let us now turn to a case that, according to Frey, is associated with a special pragmatic interpretation in the left periphery. Frey argues that movement of a constituent from an embedded clause ('long movement') to the left periphery necessarily results in contrast (53), whereas short movement of the same element, as seen above (50), does not: 
(53) I will tell you something about Max.

[Den MAX] meint Maria, dass unsere Gruppe $t_{i}$ unterstützen

the.ACC Max thinks Maria that our group support

sollte (und nicht den Hans).

should (and not the.ACC Hans

'Maria thinks that our group should support Max (and not Hans).'

What is important in our context is that this observation also holds for resultative predicates such as the following adjectival case:

(54) GRÜN wird Maria die Tür streichen (und nicht rot). green will Maria the door paint (and not red)

'Maria will paint the door green (and not red).'

In (54), the constituent grün receives focal stress and is interpreted contrastively. Needless to say, it is not base-generated in the highest position of the TP-zone. Crucially, in contrast to the case given in (50), grün cannot be moved to the position that hosts topical material, as represented in (55); cf. Frey (2004a: 19):

(55) * [CP dass ('that') [TopicP grün ${ }_{\mathrm{i}}$ [TP Maria [vP die Tür $\mathrm{t}_{\mathrm{i}}$ streichen wird]]]]

As (55) represents, (54) cannot result from Formal Movement and thus grün has reached its position via another type of movement ('long Ā-movement'), which can be depicted as follows:

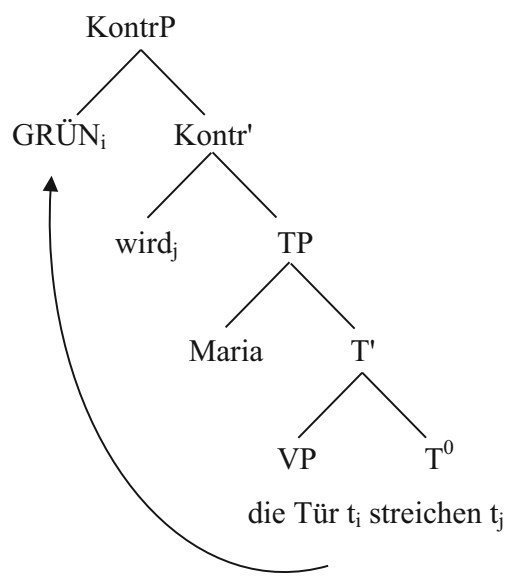

As (56) illustrates, this type of movement differs syntactically from other ways to fill the German left periphery. Crucially, as Frey also claims, it is the only type of movement to the left periphery that is associated with focal stress on the moved item 
and with a special pragmatic interpretation. As a consequence, Frey assumes that grün moves to the specifier position of a functional projection that hosts contrastive elements (KontrP). ${ }^{6}$ Given these structural facts about the German left periphery, we now argue that a similar account can be employed for the patterns of particle topicalization we have observed in this paper. However, we will see that some refinement is in order.

As already pointed out by Zeller's (2003) acceptability study, verb particles that are felicitous in the context of topicalization (movement from the same clause to SpecCP) are ruled out in scrambling constructions (adjunction to IP or VP, according to Zeller). In this respect, verb particles and PPs differ sharply, as shown by the patterns in (57) and (58).

(57) a. (dass) aus dem Wagen (eigentlich) die Männer gestiegen sind that out the.DAT car actually the men climbed are '... that the men stepped out of the car'

b. Aus dem Wagen sind (eigentlich) die Männer gestiegen.
a. ??(dass) aus (eigentlich) die Männer gestiegen sind. that PART(out) actually the men climbed are
'... that the men stepped out of the car'
b. AUS sind (eigentlich) die Männer gestiegen.

Heine et al. (2010) support these judgments by claiming that examples like (58a) are not attested in corpora at all. The main point here is that a topic reading of the particle in the middle field is excluded. This might be different for focal readings, see our discussion below.

Coming back to the movement distinctions argued for by Frey (2004a), we can interpret the asymmetry in (57) and (58) as pointing to the conclusion that the fronting of verb particles is necessarily associated with a special pragmatic interpretation (60), whereas the pragmatic interpretation of PPs is already established in the middle field (59).

\footnotetext{
${ }^{6}$ By using 'kontrast' in lieu of 'contrast', Frey makes sure to refer to the narrow notion of contrastive focus and thereby adopts a terminological convention according to which "the idiosyncratic spelling indicates that the term is not to be understood as covering all instances of what has been dubbed contrast in semantics, syntax, and phonology" (Vallduví and Vilkuna 1998: 81).
} 
(59)

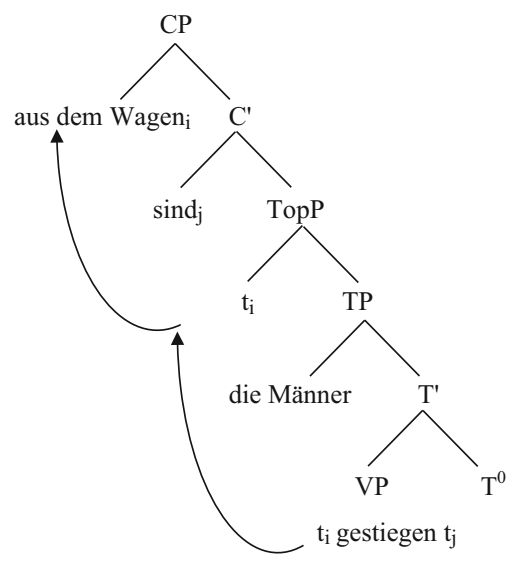

(60)

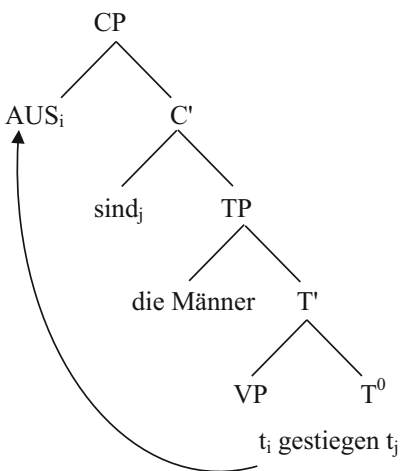

Observe that scrambling is ruled out for all particle verb classes that allow particle topicalization.

(61) a. *(dass) auf (eigentlich) der Chef die Tür gemacht that PART(open) actually the boss the door made
hat.
(cf. (5a))

has

' $\ldots$ that the boss opened the door.'

b. *(dass) runter (eigentlich) sein Chef ihn gemacht that PART(down) actually his boss him made

hat.

has

'... that his boss put him down/heavily criticized him.'

Note that a verb particle can occur to the right of a complementizer, but in this case it moves to SpecKontrP again, since, according to Frey, the complementizer occurs in the C-position above KontrP. The following data show that so-called focus 
scrambling of the particle is not movement to a position in the middle field of the clause:

(62) a. AUF hat Otto die Tür gemacht.

(Frey 2004a: 32) PART(open) has Otto the door made

b. weil AUF Otto die Tür gemacht hat. because PART(open) Otto the door made has

c. *Otto hat AUF die Tür gemacht.

d. *weil Otto AUF die Tür gemacht hat.

Since $a u f$ can only target the position right-adjacent to the complementizer, cf. (62b) vs. (62d), it is reasonable to assume an interaction between the C-domain and the option of moving the particle. (62c) shows that auf cannot move when the prefield is occupied, lending further support to this idea. Since this dependency would be highly implausible if movement of auf targeted a TP-internal position, Frey argues that it is actually long movement to KontrP (see Frey 2010: 14311434 for discussion).

That means that all cases of particle fronting must target a position in the left periphery associated with a special pragmatic interpretation, as Frey suggests. However, given that the particle in rausschmeißen as well as particles in several other verbs are negatively specified for the feature of contrastability (as we showed in Sect. 2), it is not reasonable to claim that the relevant pragmatic interpretation can be captured by the notion of contrast alone. Interestingly, in a recent reconsideration of his account, Frey (2010) comes to a similar conclusion when looking at the pragmatics of certain instances of movement to the left periphery in more detail.

In particular, cases such as the following demonstrate, according to Frey (2010), a speaker-related notion of emphasis or mirativity, in addition to information structural effects (for related cross-linguistic evidence, cf. Cruschina 2012; Bayer 2001; Bayer and Dasgupta 2014).

(63) Wie hat denn Steffi Graf im Turnier gespielt?

'How did Steffi Graf do in the tournament?'

a. VERLOREN hat sie!

lost has she

b. Sie hat VERLOREN!

she has lost

'She lost!'

Verloren in both marked (63a) and unmarked word order (63b) is the answering term to the question in (63), and thus the information focus; however, (63a) sounds more felicitous in this context. This is because the marked order in (63a) emphasizes the fact that Steffi Graf lost a tennis tournament as remarkable and unexpected, provided the common ground of speaker and hearer that Steffi Graf, at the time of utterance, is the world's greatest tennis player. Recall now our example (27a), repeated here for convenience: 
(64) RAUS hat Costa Rica die Engländer geschmissen! PART(out) has C. R. the English.PL thrown

'The team of Costa Rica kicked out the English team!'

As is the case in (63a), the speaker in (64) presents the elimination of England by Costa Rica as a highly remarkable and unexpected fact. We thus argue that elements targeting a pragmatically relevant position in the left periphery (in the model sketched by Frey) are licensed in this position by either of the following conditions:

(65) a. the displaced element can be construed contrastively, or

b. the displaced element denotes (a part of) a propositional content ranked high on a scale of remarkability.

On the one hand, cases such as (63a) can arguably meet both conditions: verloren can either be construed contrastively, e.g., in a corrective context, or express that the denoted event is highly remarkable and unexpected on the part of the speaker. On the other hand, clear cases of felicitous particle topicalization typically can either meet the requirement in (65a) in the case of [+contrast] examples or the requirement in $(65 \mathrm{~b})$. The class of expressive particle verbs (Sect. 2) is particularly suitable for meeting the requirement in (65b) because of its inherent denotation of a remarkable event.

In what follows, we need to answer two questions concerning the syntactic implementation of our cases that do not involve contrastability: (i) what kind of operator in the left periphery licenses the movement in the expressive cases, and (ii) what elements move to the left periphery in the case of fronting noncontrastable particle verbs? Let us first turn to the issue concerning the operator.

Turning to compositional accounts of exclamations, we find an elaborate semantic proposal by Rett (2011) who argues for an operator 'E-FORCE', which, like other illocutionary force operators, is a function from propositions. This operator is claimed to be appropriate for both sentence exclamations and exclamatives (and the two different types of expectation violations scalar and non-scalar they involve, see Sect. 3.1 above). Both utterance types, according to Rett, express that a specific proposition was unexpected by the speaker, and thus they form a natural class of speech act.

We would like to argue, however, that 'E-FORCE' would be a misnomer for our cases of emphatic frontings. Note that we find similar effects of unexpectedness (and not contrastive focus) due to marked word order in utterance types that should be classified as (polar) questions at the level of illocutionary force ${ }^{7}$ :

(66) a. Du fährst morgen ans Meer? you go tomorrow to.the seaside

b. Ans MEER fährst du morgen?

to.the seaside go you tomorrow

\footnotetext{
${ }^{7}$ We thank Silvio Cruschina for discussing these cases with us.
} 
Given such cases, we argue, in accordance with Bianchi et al. (2016), that the respective operator responsible for the effect of unexpectedness should be below illocutionary force, as also suggested by Trotzke and Turco (2015) in a different context:

(67) $\left[\right.$ ForceP $\left[\right.$ EmpP $\operatorname{raus}\left[\operatorname{Emp}_{[\text {contrast }] /[\text { intensity }]}^{0} \ldots\right.$ [vp... raus...]]]]

The representation suggests a Split-CP approach according to which German has left peripheral positions for encoding both the effect of emphasis and the determination of the illocutionary force of a clause. The representation makes two specific claims: First, we propose that the Force operator scopes over the emphasis operator, and thereby we suggest that emphasis is independent of the respective force of an utterance. Second, note that our discussion of topicalizing verb particles has shown that these fronting constructions can either be interpreted with a narrow focus on the particle ('KontrP', in the sense of Frey) or in an exclamatory fashion as was the case with fronting certain non-contrastable particles. To account for this complementary distribution, Trotzke and Turco (2015) suggest a clear-cut distinction between two types of emphasis (borrowing terms from the phonetic literature): 'emphasis for contrast' and 'emphasis for intensity' (first mentioned by Coleman 1914). While emphasis for contrast is typically associated with contrastive or corrective focus, emphasis for intensity, on the other hand, has to do with expressive and attitudinal evaluation (Niebuhr 2010). In syntactic terms, the emphasis projection responsible for those two interpretational options has two flavors: $\mathrm{Emp}_{\text {[contrast] }}^{0}$ and $\mathrm{Emp}_{\text {[intensity] }}^{0}$, as depicted in (67). These two flavors of $\mathrm{C}$ syntactically represent the two conditions for pragmatically relevant movement defined in (65).

Let us now turn to issue (ii): what elements move to the left periphery in the case of non-contrastable particles? Note first that, in contrast to cases where the adjunct scopes over the fronted particle (e.g., Weit hinaus ist der Ball geworfen worden $=(24)$ above), adjuncts such as regelrecht scope over the whole predicate, cf. also Dehé's (2002: 45) observation that modifiers such as right, when added to a non-directional particle, modify the entire VP. There are different possibilities to account for the scopal behavior of such examples.

First, one could argue that the whole verbal complex was part of the prefield and that the verb was scrambled back afterwards. There are many theoretical arguments against such an analysis (Fanselow and Lenertová 2011). Second, one could claim that the semantics of the whole particle verb is present on the particle and that adjuncts such as regelrecht then attach to particles. Müller (2002: 289 290) argues that this is a highly unattractive approach if the analysis should also hold for the fronting of parts of idioms as in (68a). One would not want to claim that the meaning of the whole idiom is 'on' den Löffel, in this case:

(68) den Löffel abgeben ('to die', lit. 'the spoon pass') (Trotzke and Zwart 2014: 138)

a. [Den LÖffel] hat er abgegeben.

the spoon has he passed

b. [Den LÖffel abgegeben] hat er.

'He died.' 
An analysis that would make sense both for idioms and for our cases has been suggested by Fanselow (2003: 39) and is represented in (69), cf. also Den Dikken (2002: 149 150, fn. 5) and Zeller (2001: 99, fn. 27).

(69) a. Er macht $_{\mathrm{i}}$ [vP sie regelrecht runter $\mathrm{t}_{\mathrm{i}}$ ] he makes her downright PART(down)

b. Er macht $\mathrm{sie}_{\mathrm{j}}\left[\mathrm{vv}_{\mathrm{P}} \mathrm{t}_{\mathrm{j}}\right.$ regelrecht runter $\mathrm{t}_{\mathrm{i}}$ ]

c. $\left[\mathrm{ve}_{\mathrm{j}} \mathrm{t}_{\mathrm{j}} \text { regelrecht runter } \mathrm{t}_{\mathrm{i}}\right]_{\text {macht }_{\mathrm{i}}}$ er $^{\mathrm{sie}} \mathrm{j}_{\mathrm{j}}$

On standard assumptions, an object can be removed from VP when it undergoes scrambling (69b). Therefore, a structure such as (69b) can arise in which the particle (optionally accompanied by a modifier) is the only element left in the VP-domain. When such a VP is then attracted to SpecCP, due to an emphasis operator as suggested above, the resulting configuration is $(69 \mathrm{c})$ where the verb particle (together with the modifier) is the only visible element in the prefield. This 'evacuation analysis' is motivated on independent grounds, and the fact that verb particles cannot be scrambled (see above) would be due to the fact that VPs cannot be scrambled (again, with non-focal, neutral intonation). In addition, this analysis enables adverbs to pied-pipe along with the particle, retaining their scope over the whole predicate. ${ }^{8}$ Let us briefly see how this analysis works for some cases of fronting non-contrastable verb particles.

For (16) and (20b), repeated here as $(70 \mathrm{a}, \mathrm{b})$ for ease of reference, there is evidence that the fronted category is VP and that therefore a derivation as in (69) also holds for these cases.

(70) a. Nein, [nicht ab] muss er nehmen, sondern zu.

b. [Richtig auf] regt mich im Moment, wie...

In (70b), the adverb richtig ('very, really') modifies the whole verb-particle combination aufregen 'to upset' ([-contrast, -autonomous $]$ ). If the fronted category is a remnant VP including a copy of the verb, these scoping possibilities are expected. The same argument applies to (70a): if we want to exclude a metalinguistic reading, we are forced to conclude that the negation nicht scopes over the whole verb abnehmen 'to lose weight', which is again only predicted if the moved category contains a copy of the verb. Since the particle $a b$ in abnehmen is specified as [-autonomous], it lacks the possibility to be negated in the first place. One can find many more corpus examples where the particle and some other

\footnotetext{
${ }^{8}$ Even critics of this kind of analysis concede that remnant VP movement is necessary to account for cases like (i), cf. Fanselow and Lenertová (2011: 195):

(i) What did you do on Helgoland in the evenings?

[VP [PP Mit den Hühnern] [PP ins Bett] $\left.\mathrm{t}_{\mathrm{i}}\right]_{\mathrm{j}}$ bin ich gegangen $\mathrm{t}_{\mathrm{i}}$. with the chicken into bed am I gone

'I went to bed early.'

If one wants to keep the generalization that only one constituent can precede the finite verb under V2, one must assume that (i) involves extraction of the lexical verb from the VP and subsequent fronting of the remnant to SpecCP.
} 
VP-internal element front together and show analogous scoping properties (cf. Müller 2002: 287 289). ${ }^{9}$

In other cases, however, we see that the fronted category is the particle constituent only. Consider the following constructions, displaying zumachen 'to close' ([+contrast, +autonomous $]$ ) and aufreißen 'to rip open' ([-contrast, +autonomous]), respectively:

(71) a. [Ganz zu $]$ machte er die Tür nicht. completely PART(closed) made he the door NEG 'He didn't push the door completely closed.'

b. [Halb /Ganz auf] hat er den Brief gerissen. halfway completely PART(open) has he the letter ripped 'He ripped the letter halfway/completely open.'

In both (71a) and (71b), the degree adverbs appearing in the left periphery can scope over the particles only, modifying their denotations. Accordingly, the fronted constituent can be argued to be a particle phrase PrtP containing an adverbial modifier:

(72) $[$ PrtP $[$ AdvP ganz/halb $][\operatorname{PrtP}$ zu/auf $]] \ldots \mathrm{C}^{0}$

Let us take stock. In this section, building on Frey's (2004a et seq.) approach, we proposed an emphasis operator that represents the two flavors of $\mathrm{C}$ associated with pragmatically relevant fronting of verb particles in German. In addition, we showed how the scopal properties of certain particle verb constructions involving noncontrastable particles can be retained even in fronting configurations. In sum, we demonstrated that an extended version of the left peripheral syntax argued for by Frey is uniquely able to predict the distribution of topicalized particles. Specifically, we proposed the distinction between left peripheral 'emphasis for contrast' and left peripheral 'emphasis for intensity' in this context. In the last section, we will briefly point out additional issues that might be relegated to performance constraints rather than to aspects that would have to be encoded in the grammar of the German clause.

\subsubsection{Performance constraints on particle topicalization}

At this point, a qualification is in order. In the preceding sections, we referred to both particles like $a b$, an, auf, aus, zu and particles like raus, rein, runter as belonging to a uniform morphological class of particles. However, as is well known

\footnotetext{
9 While agreeing with our remnant movement analysis, a reviewer points out that not everything that should be considered part of the VP is able to front together with a particle, cf. questionable examples with, e.g., low datives:

(i) * Dieser Gefahr aus setzt keine Mutter ihr Kind.

this.DAT danger PART(out) put no mother her child

'No mother exposes her child to such a danger.'
}

Neither we nor the reviewer have a solution for these cases. However, since we think that our analysis in (69) and (70) is the most theoretically sensible option for the cases involving adjuncts and particles discussed in our paper, we leave these remaining issues for future work. 
Table 1 'Single' versus 'double' particles in German (sample)

\begin{tabular}{ll}
\hline Single & Double (hin, her, and $r$ denote directions) \\
\hline ein ('in') & hin ein, her ein, r ein \\
aus ('out') & hin aus, her aus, r aus \\
auf ('on') & hin auf, her auf, r auf \\
unter ('under') & hin unter, her unter, r unter \\
an ('on, next to') & her an, r an \\
zu ('to') & hin zu \\
weg ('away') & hin weg \\
ab ('off') & hin ab, her ab \\
\hline
\end{tabular}

from the literature (Zeller 2001; McIntyre 2001), the former class is morphologically simple, while the latter is morphologically complex. McIntyre (2001) dubs them 'single' and 'double' particles, respectively, see Table $1 .{ }^{10}$

Double particles consist of single particles and a functional morpheme (e.g., hin, her or $r$ ) denoting both directionality and referential force (McIntyre 2001). While our examples of expressive particle verbs have featured only double particles, note that single particles can appear in expressive particle verb combinations too. As an example, consider the following contrast, making use of the diagnostics introduced in Sect. 2.

(73) a. Er ist auf der Party total abgegangen.

he is at the party full-on PART(off).gone

'He freaked out at the party.'

b. Was ist er auf der Party abgegangen!

what is he at the party PART(off).gone

'How he freaked out at the party!'

(74) a. ?? Der Minister hat den Posten total abgegeben.

the minister has the position full-on PART(off).given

'The minister has ceded the position.'

b. ?? Was hat der Minister den Posten abgegeben!

what has the minister the position PART(off).given

'How the minister ceded the position!'

Quite surprisingly, the third factor characterizing expressive particle verbs, the possibility of particle topicalization, seems less acceptable in cases such as abgehen:

(75) ? $\mathrm{AB}$ ist er auf der Party gegangen!

PART(off) is he at the party gone

\footnotetext{
${ }^{10}$ There is no consensus, however, whether 'double' particles are to be considered as particles or as postpositions. While McIntyre (2001); Stiebels (1996); Svenonius (2003) assume that the former is the case, Zeller (2001); Aelbrecht and Den Dikken (2013) argue instead that these elements have to be regarded as postpositions.
} 
Given that the German prefield is usually quite liberal with respect to the moved phrase, it is reasonable to assume that the internal structural makeup of particles does not qualify as a convincing restriction on topicalization possibilities (for elaborate proposals of the internal makeup of particles, cf. Noonan 2010 for German; and Svenonius 2010 for English).

In fact, under our account of emphatic fronting in terms of remnant VP movement, structural complexity of the particle is not predicted to play a role: with both single and double particles, the fronted category is a VP containing a copy of (minimal) V:

(76) a. [vp ab en ist er auf der Party gegangen [vp (= 75)

b. [vP raus ] ist er geflogen [vp (=25a)

Interestingly, the particle $a b$ seems to be recalcitrant to fronting even when it contributes a clear spatial semantics. In the following minimal pair, the particle verbs $a b$-schicken and weg-schicken are synonyms. In particular, both weg and $a b$ are single particles, and they can be assigned quite similar denotations (cf. Stiebels 1996: 95). However, they clearly differ in the acceptability of constructions with the particle fronted to the prefield (see Kratzer 1994 for the original discussion):

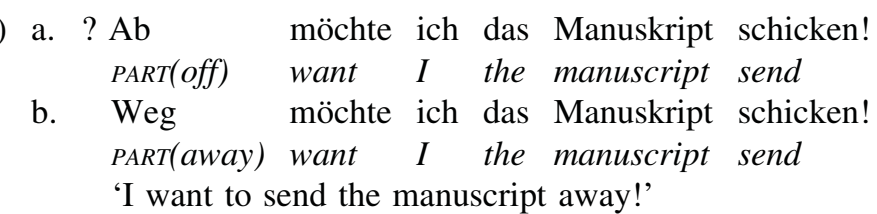

Nonetheless, the particles do not exhibit the same value with respect to the feature [ \pm autonomous]. As (78) shows, the resultative weg is semantically more autonomous than the particle $a b$ :

(78) a. * Das Manuskript ist ab.

b. Das Manuskript ist weg.

We thus hypothesize that the presence of a [+autonomous] particle in the fronted VP improves the acceptability of the resulting construction. If this is true, the ameliorating role played by autonomy could be explained as a performance effect: the presence of a semantically highly autonomous item would qualify as a positive cue in the parsing of sentences where the particle is spelled out in the prefield and the lexical verb is not spelled out in an adjacent position. With [+autonomous] particles, at least a part of the denotation of the fronted VP can be established immediately, whereas [-autonomous] particles would require the speaker to wait until reconstruction for the denotation of the VP to be derived (cf. Heine et al. 2010: 4852 for discussion). This might suggest that not only the two pragmatic conditions we stated above (involving both [-autonomous] and [+autonomous] cases) are relevant in licensing emphatic fronting, but performance components are as well. 
This aspect of particle topicalization again shows that not every aspect relevant for the displacement of verb particles should be syntactically encoded. As we already argued in Sect. 3.1, while there is good evidence that predicate/argument relations are part of VP syntax, features like both contrast and expressivity are more profitably captured at the later derivational stage of Spell-Out at LF. Consequently, we obtain a derivationally distributed conception of idiomaticity. Given this picture, we proposed that if particles are moved to the left periphery, they must target a position that is related to a special pragmatic interpretation that, as we argued, cannot solely be identified by the information structural notion of contrast. Instead, we suggested a notion of left peripheral emphasis that can capture the displacement of either elements that can be construed contrastively or elements denoting an upper point on a scale of remarkability.

\section{Conclusion}

In this paper, we started from the observation that some syntactic operations are sensitive to the transparency divide of particle verbs, while others are not. We focused on topicalization as an operation that shows sensitivity in this context, thereby illustrating two possible approaches (Sect. 1.1). To gain a detailed picture of the whole transparency spectrum of particle verb combinations, we proposed a new classification that not only distinguishes between fully transparent and fully non-transparent particle verbs, but also identifies intermediate classes, which capture different degrees of dependency between the verb and the particle (Sect. 1.2). We showed that the picture is even more complicated by pointing out the existence of the additional class of expressive particle verbs, detected by distinct grammatical properties (Sect. 2). Finally, we explored to what extent the distinctions we demonstrated so far must be represented in the grammar (Sect. 3). We concluded that not every aspect relevant for particle topicalization should be syntactically encoded (Sect. 3.1). Given the picture we suggested, we then provided a unified account of left-periphery-movement of verb particles (Sect. 3.2) by arguing for a composite notion of emphasis that can serve as a unified feature driving the topicalization patterns we discussed. We finally pointed out some further issues that might be relevant for future research.

Acknowledgments We thank Sjef Barbiers, Josef Bayer, Daniel Büring, Silvio Cruschina, Marcel den Dikken, Verner Egerland, Constantin Freitag, Werner Frey, Joachim Jacobs, Christoph Schwarze, Eva Wittenberg, Susi Wurmbrand, Jan Wouter Zwart, and three anonymous reviewers for useful comments and discussion. Thanks also to audiences at the University of Stuttgart and the CGSW 30 conference at the University of Chicago. All remaining errors and shortcomings are our own. We gratefully acknowledge financial support from the German Research Foundation (DFG Grants BA 1178/9 1 and TR $1228 / 2$ 1) and from the DFG Excellence Initiative (University of Konstanz, Project No. 440/15).

\section{References}

Aelbrecht, Lobke, and Marcel den Dikken. 2013. Preposition doubling in Flemish and its implications for the syntax of Dutch PPs. The Journal of Comparative Germanic Linguistics 16: 3368 . 
Bayer, Josef. 2001. Asymmetry in emphatic topicalization. In Audiatur Vox Sapientiae: A Festschrift for Arnim von Stechow, ed. Caroline Féry, and Wolfgang Sternefeld, 15 47. Berlin: Akademie.

Bayer, Josef, and Probal Dasgupta. 2014. Emphatic topicalization and the structure of the left periphery: Evidence from German and Bangla. Syntax.

Bianchi, Valentina, Giuliano Bocci, and Silvio Cruschina. 2016. Focus fronting, unexpectedness, and the evaluative dimension. Semantics and Pragmatics. doi:10.3765/sp.9.3.

Cappelle, Bert. 2008. The grammar of complex particle phrases in English. In Syntax and semantics of spatial P, ed. Anna Ashbury, Jakub Dotlacil, Berit Gehrke, and Rick Nouwen, 103 145. Amsterdam $\&$ Philadelphia: Benjamins.

Chomsky, Noam. 1995. The minimalist program. Cambridge, MA: MIT Press.

Coleman, H.O. 1914. Intonation and emphasis. Miscellanea Phonetica 1: 626.

Corver, Norbert. 2015. Interjections as structured root expressions. In Representing structure in phonology and syntax, ed. Marc van Oostendorp, and Henk van Riemsdijk, 41 84. Berlin \& New York: Mouton de Gruyter.

Cruschina, Silvio. 2012. Discourse related features and functional projections. Oxford: Oxford University Press.

Dehé, Nicole. 2002. Particle verbs in English: Syntax, information structure and intonation. Amsterdam $\&$ Philadelphia: Benjamins.

Dehé, Nicole. 2015. Particle verbs in Germanic. In Word formation: An international handbook of the languages of Europe, ed. Peter O. Müller, Ingeborg Ohnheiser, Susan Olsen, and Franz Rainer, 611 626. Berlin \& New York: Mouton de Gruyter.

den Dikken, Marcel. 2002. Review of particle verbs and local domains by Jochen Zeller. The Journal of Comparative Germanic Linguistics 4: 145169.

Elliott, Dale E. 1974. Toward a grammar of exclamation. Foundations of Language 11: 231246.

Engel, Ulrich. 1977. Syntax der deutschen Gegenwartssprache. Berlin: Erich Schmidt Verlag.

Erteschik Shir, Nomi. 2007. Information structure: The syntax discourse interface. Oxford: Oxford University Press.

Fanselow, Gisbert. 2003. Surprising specifiers and cyclic spellout. Generative Linguistics in Poland 5: 2946.

Fanselow, Gisbert, and Denisa Lenertová. 2011. Left peripheral focus: Mismatches between syntax and information structure. Natural Language \& Linguistic Theory 29: 169209.

Frey, Werner. 2004a. The grammar pragmatics interface and the German prefield. Sprache und Pragmatik 52: 139.

Frey, Werner. 2004b. A medial topic position for German. Linguistische Berichte 198: 153190.

Frey, Werner. 2010. Ā Movement and conventional implicatures: About the grammatical encoding of emphasis in German. Lingua 120: 14161435.

Gallego, Ángel J. 2010. Phase theory. Amsterdam \& Philadelphia: Benjamins.

Heine, Antje, Joachim Jacobs, and Robert Külpmann. 2010. Quer zu den Feldern: Zur Topologie von Partikelverben. Linguistische Berichte 221: 3760.

Hetzron, Robert. 1975. The presentative movement or why the ideal word order is V.S.O.P. In Word order and word order change, ed. Charles N. Li, and Sandra Thompson, 346 388. Austin: University of Texas Press.

Jackendoff, Ray. 2002. English particle constructions, the lexicon, and the autonomy of syntax. In Verb particle explorations, ed. Nicole Dehé, Ray Jackendoff, Andrew McIntyre, and Silke Urban, 6794. Berlin \& New York: Mouton de Gruyter.

Kratzer, Angelika. 1994. The event argument and the semantics of voice. Ms., UMass Amherst.

Lambrecht, Knud. 2000. When subjects behave like objects: An analysis of the merging of S and $\mathrm{O}$ in sentence focus constructions across languages. Studies in Language 24: 611682.

Leonetti, Manuel, and Victoria Escandell Vidal. 2009. Fronting and verum focus in Spanish. In Focus and background in Romance languages, ed. Andreas Dufter, and Daniel Jacob, 155204 Amsterdam \& Philadelphia: Benjamins.

Lohse, Barbara, John A. Hawkins, and Thomas Wasow. 2004. Domain minimization in English verb particle constructions. Language 80: 238261.

Lüdeling, Anke. 2001. On particle verbs and similar constructions in German. Stanford: CSLI Publications.

McIntyre, Andrew. 2001. German double particles as preverbs: Morphology and conceptual semantics. Tübingen: Stauffenburg. 
McIntyre, Andrew. 2002. Idiosyncrasy in particle verbs. In Verb particle explorations, ed. Nicole Dehé, Ray Jackendoff, Andrew McIntyre, and Silke Urban, 95 118. Berlin \& New York: Mouton de Gruyter.

McIntyre, Andrew. 2015. Particle verb formation. In Word formation: An international handbook of the languages of Europe, ed. Peter O. Müller, Ingeborg Ohnheiser, Susan Olsen, and Franz Rainer, 434 449. Berlin \& New York: Mouton de Gruyter.

Morzycki, Marcin. 2012. Adjectival extremeness: Degree modification and contextually restricted scales. Natural Language \& Linguistic Theory 30: 567609.

Müller, Stefan. 2002. Complex predicates: Verbal complexes, resultative constructions and particle verbs in German. Stanford: CSLI Publications.

Niebuhr, Oliver. 2010. On the phonetics of intensifying emphasis in German. Phonetica 67: 170198.

Noonan, Máire. 2010. Á to zu. In Mapping spatial PPs, ed. Guglielmo Cinque, and Luigi Rizzi, 161195. Oxford: Oxford University Press.

Norrick, Neal R. 2009. Interjections as pragmatic markers. Lingua 41: 866891.

Potts, Christopher. 2007. The expressive dimension. Theoretical Linguistics 33: 165198.

Rett, Jessica. 2011. Exclamatives, degrees and speech acts. Linguistics and Philosophy 34: 411442.

Rett, Jessica. 2015. The semantics of evaluativity. Oxford: Oxford University Press.

Rögnvaldsson, Eiríkur, and Höskuldur Thráinsson. 1990. On Icelandic word order once more. In Syntax and semantics, vol. 24: Modern Icelandic syntax, ed. Joan Maling, and Annie Zaenen, 3 40. San Diego: Academic Press.

Stiebels, Barbara. 1996. Lexikalische Argumente und Adjunkte. Berlin: Akademie Verlag.

Stiebels, Barbara, and Dieter Wunderlich. 1994. Morphology feeds syntax: The case of particle verbs. Linguistics 32: 913968.

Svenonius, Peter. 2003. Limits on P: Filling in holes vs. falling in holes. Nordlyd 31: 431445.

Svenonius, Peter. 2010. Spatial P in English. In Mapping spatial PPs, ed. Guglielmo Cinque, and Luigi Rizzi, 127 160. Oxford: Oxford University Press.

Trotzke, Andreas. 2015. Rethinking syntactocentrism: Architectural issues and case studies at the syntax pragmatics interface. Amsterdam \& Philadelphia: Benjamins.

Trotzke, Andreas, Stefano Quaglia, and Eva Wittenberg. 2015. Topicalization in German particle verb constructions: The role of semantic transparency. Linguistische Berichte 244: 407424.

Trotzke, Andreas, and Giuseppina Turco. 2015. The grammatical reflexes of emphasis: Evidence from German wh questions. Lingua 168: 3756.

Trotzke, Andreas, and Eva Wittenberg. 2016. Expressive particle verbs and conditions on particle fronting. Journal of Linguistics. doi:10.1017/S0022226716000153.

Trotzke, Andreas, and Jan Wouter Zwart. 2014. The complexity of narrow syntax: Minimalism, representational economy, and simplest Merge. In Measuring grammatical complexity, ed. Frederick J. Newmeyer, and Laurel B. Preston, 128 147. Oxford: Oxford University Press.

Vallduví, Enric, and Maria Vilkuna. 1998. On rheme and kontrast. In The limits of syntax, ed. Peter W. Culicover, and Louise McNally, 79 108. New York: Academic Press.

Wurmbrand, Susi. 2000. The structure(s) of particle verbs. Ms., McGill University.

Zeller, Jochen. 2001. Particle verbs and local domains. Amsterdam \& Philadelphia: Benjamins.

Zeller, Jochen. 2003. Moved preverbs in German: Displaced or misplaced? In The yearbook of morphology, ed. Geert Booij, and Ans van Kemenade, 179 212. Dordrecht: Kluwer. 